\section{Commentary: Outcomes and causes of late failure of valve-sparing aortic root replacement}

\author{
Christian Pizarro, MD
}

Valve-sparing aortic root replacement (VSARR) has become a preferred strategy to manage patients with aortic root aneurysm associated with connective tissue disorders and occasionally following repair of conotruncal anomalies. ${ }^{1,2}$ In this scenario, the lower morbidity and lifestyle advantages associated with preservation of the aortic valve must be balanced against the durability of this valve and the potential need for reintervention; therefore, mid- to long-term follow-up data are essential to inform this decision. For obvious reasons, this is of particular interest for patients who present with a root aneurysm during childhood or adolescence.

In this issue of the Journal, Saran and colleagues provide unique insight into the functional outcome of the valve-sparing strategy in a large cohort of patients followed for nearly a decade. ${ }^{3}$ Although the outcomes of the reimplantation and remodeling techniques were not substantially different, there were a few anatomic characteristics that seemed to play a pivotal role in the freedom from reintervention. These included the presence of a bicuspid aortic valve and the presence of annular dilatation. It was suggested that perhaps it is the additional stress exerted on the leaflets when the annulus dilates that leads to progressive valve failure. With this is mind, if a VSARR strategy is considered, theoretically an earlier intervention perhaps could mitigate this process and enhance the durability of repair. Not sure we are ready to embrace this approach.

\footnotetext{
From the Nemours Cardiac Center, Alfred I. duPont Hospital for Children, Wilmington, Del; and Sidney Kimmel School of Medicine, Thomas Jefferson University, Philadelphia, Pa.

Disclosures: The author reported no conflicts of interest.

The Journal policy requires editors and reviewers to disclose conflicts of interest and to decline handling or reviewing manuscripts for which they may have a conflict of interest. The editors and reviewers of this article have no conflicts of interest.

Received for publication Oct 23, 2020; revisions received Oct 23, 2020; accepted for publication Oct 26, 2020; available ahead of print Nov 5, 2020.

Address for reprints: Christian Pizarro, MD, Nemours Cardiac Center, Alfred I. DuPont Hospital for Children, 1600 Rockland Rd, Wilmington, DE 19803 (E-mail: Christian.Pizarro@nemours.org).

J Thorac Cardiovasc Surg 2022;164:505

$0022-5223 / \$ 36.00$

Copyright (c) 2020 by The American Association for Thoracic Surgery

https://doi.org/10.1016/j.jtcvs.2020.10.099
}

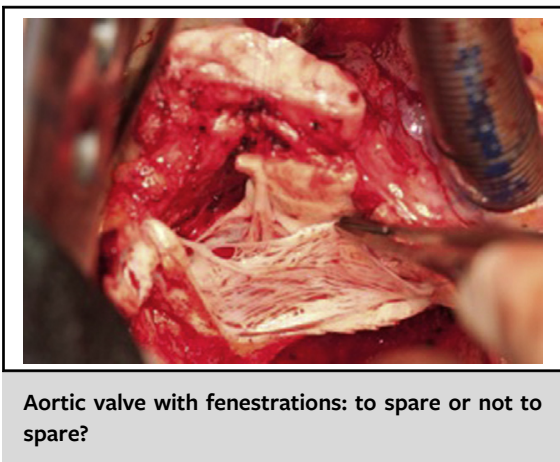

CENTRAL MESSAGE

Late failure following valvesparing aortic root replacement can be minimized by appropriate patient selection.

In addition, the most common reason for aortic valve replacement after reimplantation was due to structural cup pathology, whereas annular dilatation was the predominant issue associated with the remodeling technique. Although it seems apparent that aortic cusp reconstruction does not confer the desired durability, these 2 distinct pathophysiological mechanisms of failure should be considered when performing a VSARR procedure. Perhaps one size does not fit all.

In the current era, an aortic root aneurysm can be addressed safely and effectively almost universally; nevertheless, the decision about valve preservation is complex and represents a technical challenge. Many questions remain unanswered. Saran and colleagues provide valuable insights and raise important questions regarding the interplay among annular size, type of graft, valve morphology, and cusp pathology on durability. It is this type of analysis that could prove essential to a better understanding of how to individualize the approach to VSARR. It is entirely possible that with improved case selection, fewer patients will undergo VSARR, with improved durability and greater freedom from reintervention. I think we are making progress.

\section{References}

1. Gaudino M, Lau C, Munjal M, Avgerinos D, Girardi LN. Contemporary outcomes of surgery for aortic root aneurysms: a propensity-matched comparison of valvesparing and composite valve graft replacement. J Thorac Cardiovasc Surg. 2015; 150:1120-9.e1.

2. Pizarro C, Baffa JM, Derby CD, Krieger PA. Valve-sparing neo-aortic root replacement after Fontan completion for hypoplastic left heart syndrome. J Thorac Cardiovasc Surg. 2011;141:1083-4.

3. Patlolla SH, Saran N, Dearani JA, Stulak JM, Schaff HV, Greason KL, et al. Outcomes and risk factors of late failure of valve-sparing aortic root replacement. $J$ Thorac Cardiovasc Surg. 2022;164:493-501.e1. 